\title{
Mutations in Novel COVID-19 Make it More Dangerous: Prevention Via Scientific Approaches
}

\author{
Fatemeh Mollaamin $^{1}$ (D), Rahim Esmkhani ${ }^{2}$, Majid Monajjemi 1,*iD \\ 1 Department of Chemical Engineering, Central Tehran Branch, Islamic Azad University, Tehran, Iran \\ 2 Department of Chemistry, Khoy Branch, Islamic Azad University, Khoy, Iran \\ * Correspondence: maj.monajjemi@iauctb.ac.ir;
}

Scopus Author ID 6701810683

Received: 22.09.2020; Revised: 27.10.2020; Accepted: 29.10.2020; Published: 1.11.2020

\begin{abstract}
We computed several genomes of COVID-19 information from GISAID, NCBI, and NMDC. Sequence alignment with the strain Bat CoV RaTG13 applied by MAFFT. Genome variable zones of sequence alignment applied the noisy (http://www.bioinf.uni-leipzig.de/Software/noisy/). The protein sequences were gained from NCBI web sites, and the proteins of COVID-19, such as protein sequences, were used to analyze the conserved domain. Several proteins were used for constructing 3D compounds through homology modeling. Moreover, we show that N-terminal deletions of karyopherin alpha 2 that no longer linkage to karyopherin beta 1 retain ORF6 binding activity but no longer block STAT1 nuclear enter. Recombinant SARS-CoV lacking ORF6 did not close karyopherin alpha 2 to the ER/Golgi membrane and led to the import of the STAT1 complex into the nucleus. Some genomes of different coronaviruses applying BAST and MAFFT software have been estimated, and other genomes have been chosen. It has been unraveled that COVID-19 can generate a new mutation, especially in glycoproteins.
\end{abstract}

Keywords: GISAID; COVID-19; Mutations; RaTG13.

(C) 2020 by the authors. This article is an open-access article distributed under the terms and conditions of the Creative Commons Attribution (CC BY) license (https://creativecommons.org/licenses/by/4.0/).

\section{Introduction}

The COVID-19 viruses were nominated as SARS-CoV-2, generally based on its closest relationship with the SARS-CoV viruses. This investigation indicated that SARS-CoV-2 and SARS-CoV have the same bases, as they produce sister families and SARS-CoV-2 aggregates with two SARS-like bat viruses [1-10]. Generally, the length of the phylogenetic tree of the general ancestor of SARS (0.03) is short, while the length of SARS-CoV-2 and also two SARSlike bat viruses is longer (0.03), which illustrates there are many viruses in the range of these two lengths (0.09-0.03) that are not found up to now. One of the bat coronavirus name BatCoV RaTG13 isolated in 2013 was explored to be nearly related to SARS-CoV-2 [2-4]. So, we reconsidered some of the outgroups for investigating the root and transmission history of SARS-CoV-2. These works are significant for world public-health for preparing proper methodologies for avoiding the more spread. The recent information published indicates that the novel coronavirus SARS-CoV-2 reveals the existence of some mutations needed within infected human states, which really enhances its strength to produce human disease. With the COVID-19 pandemic having produced about 3.1 million infections and 175,000 fatalities, as of first May of 2020, public considerations are concentrated on which items the nearly high mortality rates in the population. Recently, researchers have discovered some different figures 
of the SARS-CoV-2 viruses that produce the COVID-19 pandemic. It is considered the most of those infections are asymptomatic, and the viruses can diffuse during these asymptomatic periods, producing containments the real challenges, as an indication through the current community spread of those illnesses in many countries. So, it stays viable for infection within aerosols for a few hours and on several surfaces for up to one week. The mechanism of the infection is supported by the virus gains entry to the host cell via the spike glycoprotein (S) that attaches to the ACE2 (angiotensin-converting enzyme 2) subunit to enter the cell. These receptors are explored in some tissues, including the epithelium of the nasal cavities, the lungs, Leydig, and also Sertoli, or other gastrointestinal epithelium. Some $(\approx 7)$ beta-coronaviruses show diseases in humans, with various severity that the most different part of those genomes is a part encoding the RBD (S protein receptor-binding domain). Corvid-19 spike proteins have two heptad repeats in its S2 domain. For SARS-CoV and MHV, the post-fusion structure of the HR has been done; they build a six-helix bundle. The functional task of MHV and SARSCoV HRs was approved through mutating keys residues via inhibition experiments applying HR2 peptides (Scheme 1).

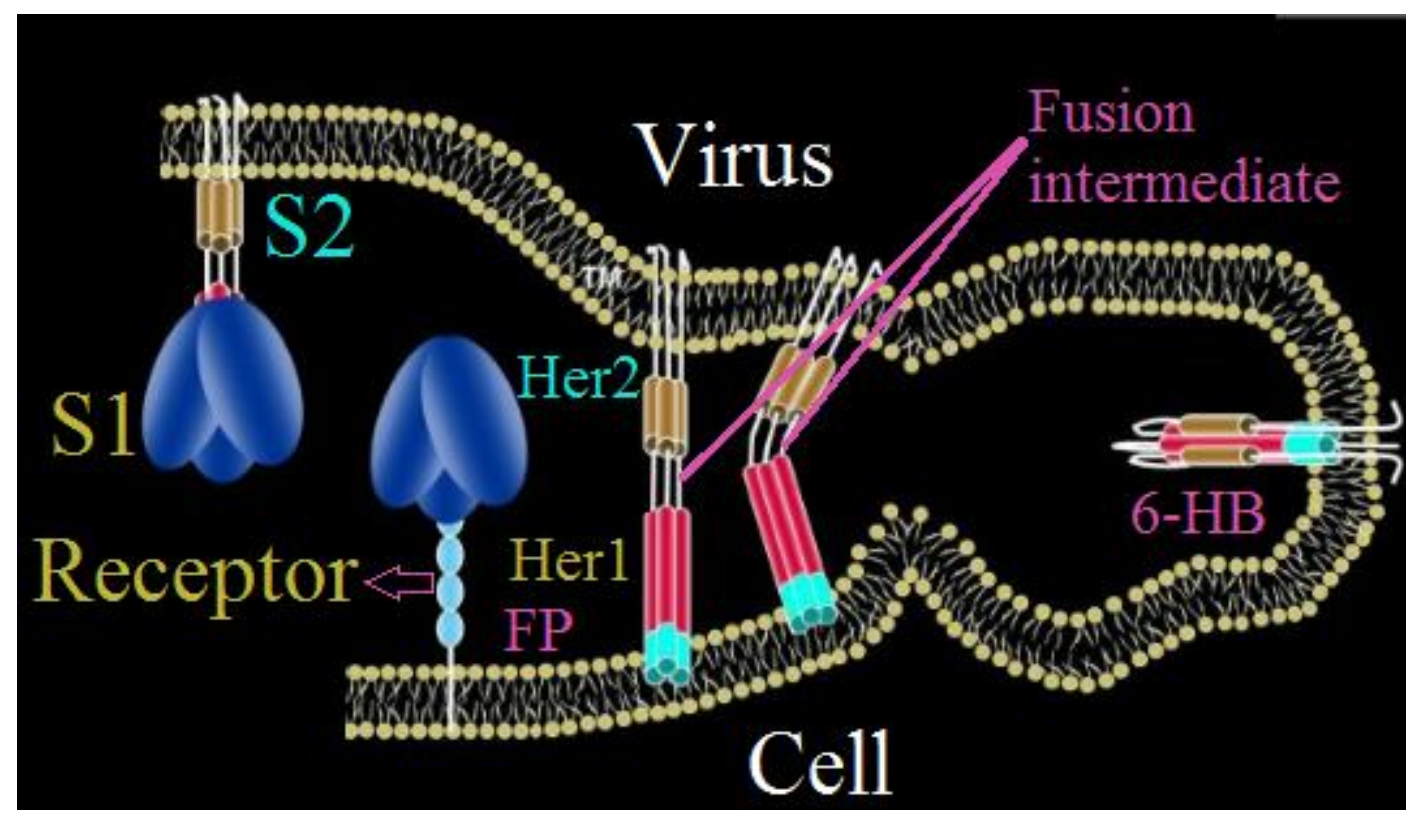

Scheme 1. Schematic of Coronavirus spike protein-mediated membrane fusion.

Multiple transformations have been built within the SARS-CoV-2 genomes in some of them comprising the addition, replacement, or deletion of single nucleotides, which are nominated SNVs "single nucleotide variant". In this paper, we are searching for more understanding of these mutations, which are dangerous for the future of the world due to the pathogenicity of the virus. Moreover, any further predictions for progressing the vaccines like new drugs to counter these diseases are required. Therefore, some of the mutations do benefits or disadvantages under special circumstances, such as some mutations are found very commonly in the S protein-ACE2 protein interface. A comparison of the lipid rafts of COVID19 has indicated that the novel strain of coronaviruses has $85 \%$ identity with high acute respiratory syndrome SARS-CoV. Different lipids such as caveolins, clathrins, and dynamin have a principal task in the internalization of viruses. Those lipids are into host cells, and targeting host lipids are being discussed as an antiviral strategy [2]. COVID-19 can be jointed to the angiotensin-converting enzyme-2 receptor on the cell membrane for enabling it to infect the host membrane upon coupled with a reliance on serine protease TMPRSS2. This 
intramolecular can be causes the virus's competence to infect the cell [3]. COVID-19 is a group of the beta-coronavirus that infects humans, which has mutated in the $\mathrm{S}$ and $\mathrm{N}$ proteins. The positive-sense RNA of COVID-19 vary from SARS and MERS, being nearly $31 \mathrm{~kb}$ and $29 \mathrm{~kb}$ [6]. The COVID-19 encoding around 30 proteins and the genome sequences indicate that COVID-19 group families have more than eighty percent identity with SARS and fifty percent with MERS [7-9]. In this work, we have compared the COVID-19 via other corona groups for discovering mutations and gaps.

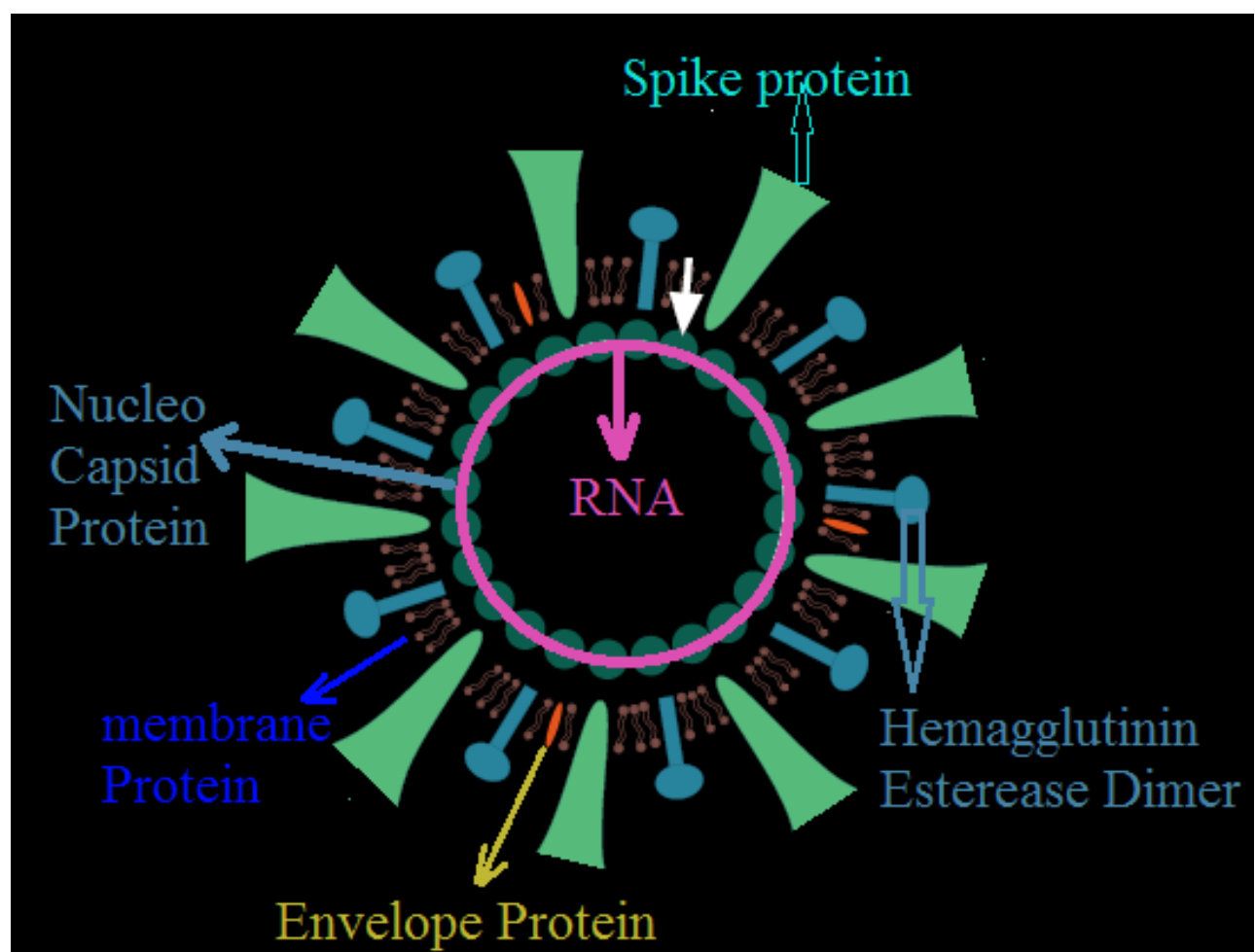

Scheme 2. The schematic structure of COVID-19 (SARS-CoV-2) consists of the following: Spike protein (S), hemagglutinin-esterase dimer (HE), a membrane glycoprotein (M), an Envelope protein (E), Nucleocapsid protein $(\mathrm{N})$, and RNA.

We get data from NCBI, and we accomplished the "FASTA \& BLAST". This consideration among genomes has been applied by the MAAFT-7 program for COVID-19. Based on these analyses, the suitable identically were compared with bat $\mathrm{CoV}$ genomes. Results indicate that all COVID-19 families were close to other same families; therefore, COVID-19 arises from a few mutations from other coronaviruses. Although genomic data does not confirm this wrong idea that COVID-19 has a laboratory root, it is impossible for disproving or proving the theories of their roots (Figs.1 \&2). For understanding COVID-19's root, its sequences have to be extracted from animal sources. The ORFs encode proteins containing spike glycoprotein, envelope protein, matrix protein, and nucleocapsid, which their abbreviations are S, E, M, and N, respectively. COVID-19 also possesses auxiliary proteins that interfere with the host's innate immune response [8]. We accomplish several ORFs for COVID-19 from GenBank, and the result showed a similarity of a large percent without any mutation in Amino Acids. Orf1ab polyprotein is expressed in the form of two polyproteins which are processed into 11 Non- structural proteins by three viral Proteases. The SARS epidemic also yields new concepts and considerations to the proteins translated from ORF1a and ORF1b of the input genome RNA, which is known as the replicase/transcriptase gene. 
Genetic information has confirmed which proteins of ORF1ab is contained in cellular signaling and modification of cellular gene expression.

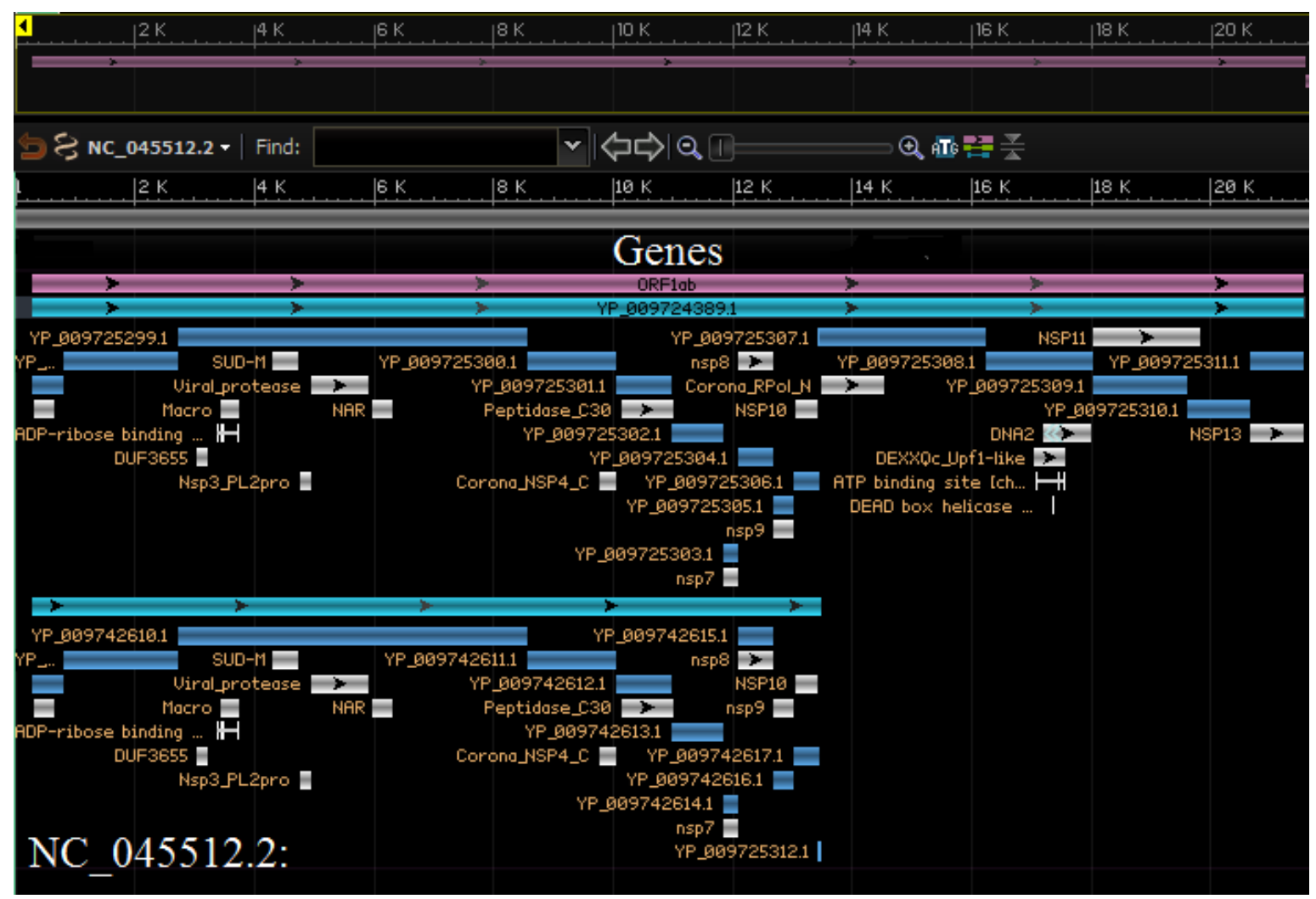

Figure 1. Severe acute respiratory syndrome coronavirus 2 isolate Wuhan-Hu-1, complete genome.

The orf1 (ab) gene merges two-thirds of the genome, encodes a total of sixteen proteins, which are nsp1, nsp2, .. up to nsp16. The other third of SARS CoV-2 includes 4 genes encode the other proteins that are known as S, M, E, N proteins, and 6 genes that encode 6 proteins, including orf3a, orf6, orf7a, orf7b, orf8, and orf10. Viral DNA replication and its analysis indicate that ORF6 is not needed for viral replication, and ORF6 deletion reduces viral DNA replication in cells. It can be shown which SARS-COV ORF6 proteins are placed to the endoplasmic reticulum (ER)/Golgi membrane in infected cells, that make complexes via $\alpha 2$ and $\beta 2$ karyopherin to the membrane.

We discussed on the region of ORF6 that binds karyopherin to the $\mathrm{C}$ terminus of $\mathrm{ORF}(6)$ and show that mutations in the $\mathrm{C}$ terminus no longer bind karyopherin $\alpha 2$ or block the nuclear import of STAT1. We also exhibit that N-terminal deletions of karyopherin $\alpha 2$, which no longer bind to karyopherin $\beta 1$, still retain ORF6 binding activity but no longer block STAT1 nuclear import. We discuss the likely implications of these data on SARS-CoV replication and pathogenesis (Figs 2\&3).

Among the SARS-CoV protein's series ORFs, the ORF3a, ORF6, ORF7a, and ORF7b are reported to be incorporated into virions.

Considerable host defense against attack pathogens is the innate immune systems that consist of secreted cytokines, intracellular signaling pathways, and the expression of type I interferon that signals to adjacent cells for inducing the antiviral states.

ORF6 protein of Coronavirus was aligned with ORF6 protein COVID-19, protein 7 , and ORF8 are equal to the ORF8, hypothetical protein Bat SARS CoV and hypothetical protein Bat SARS. 


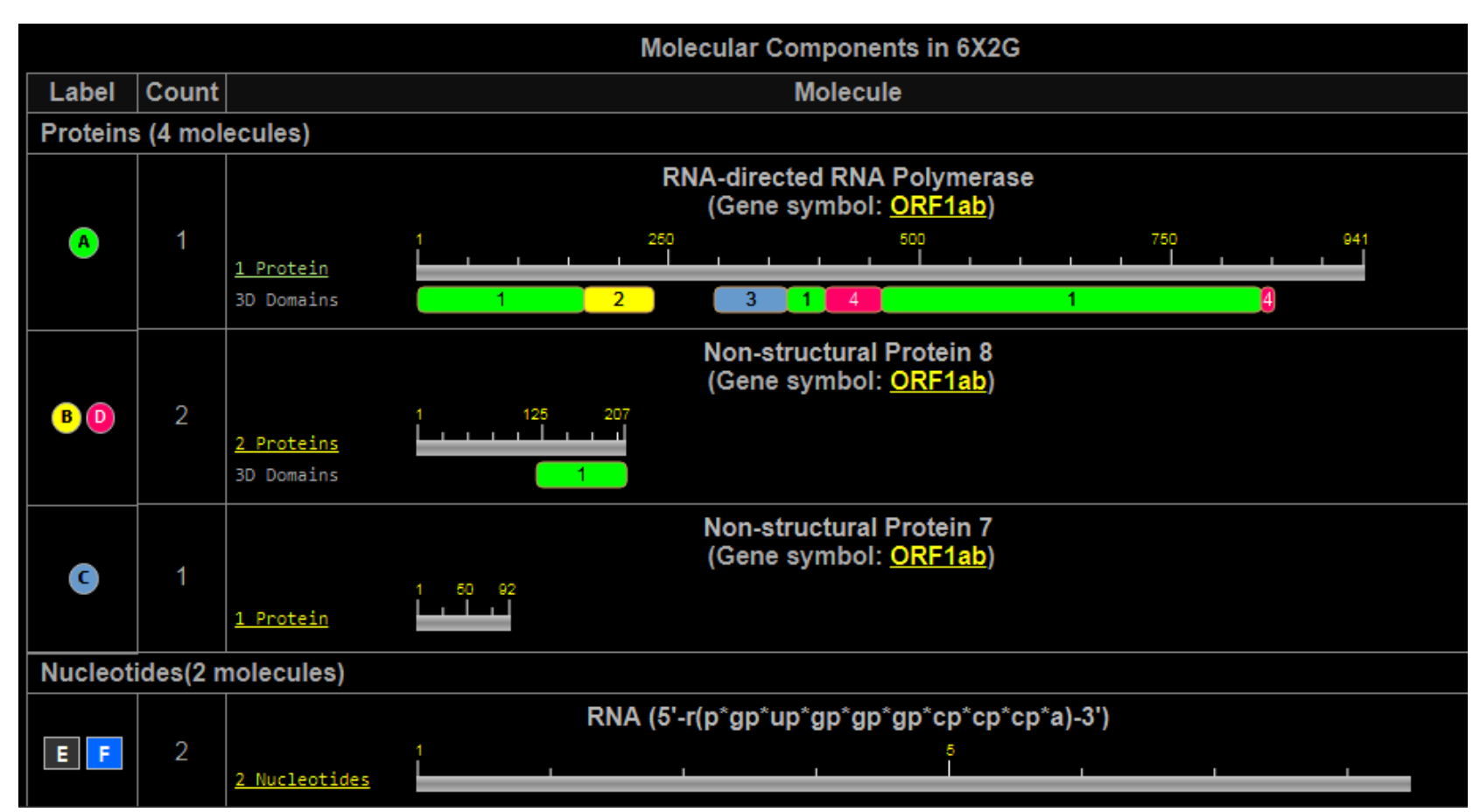

Figure 2. Sequence Display for the Entities in PDB 6X2G that shows the differences between the four sequences.

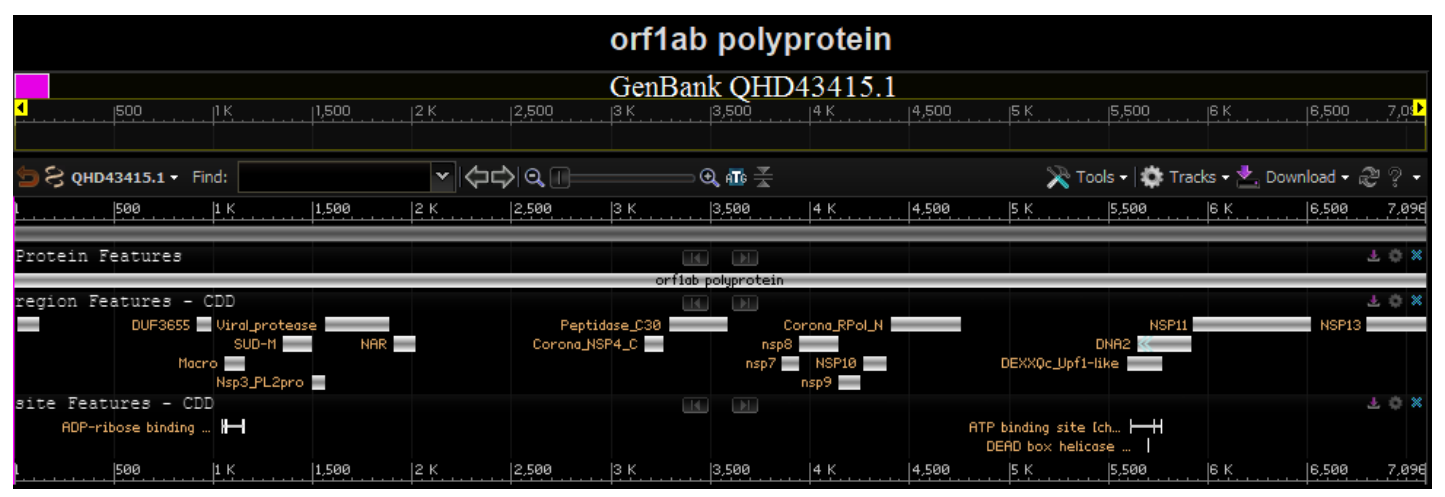

Figure 3. ORF1ab GenBank acronym: SARS-CoV-2.

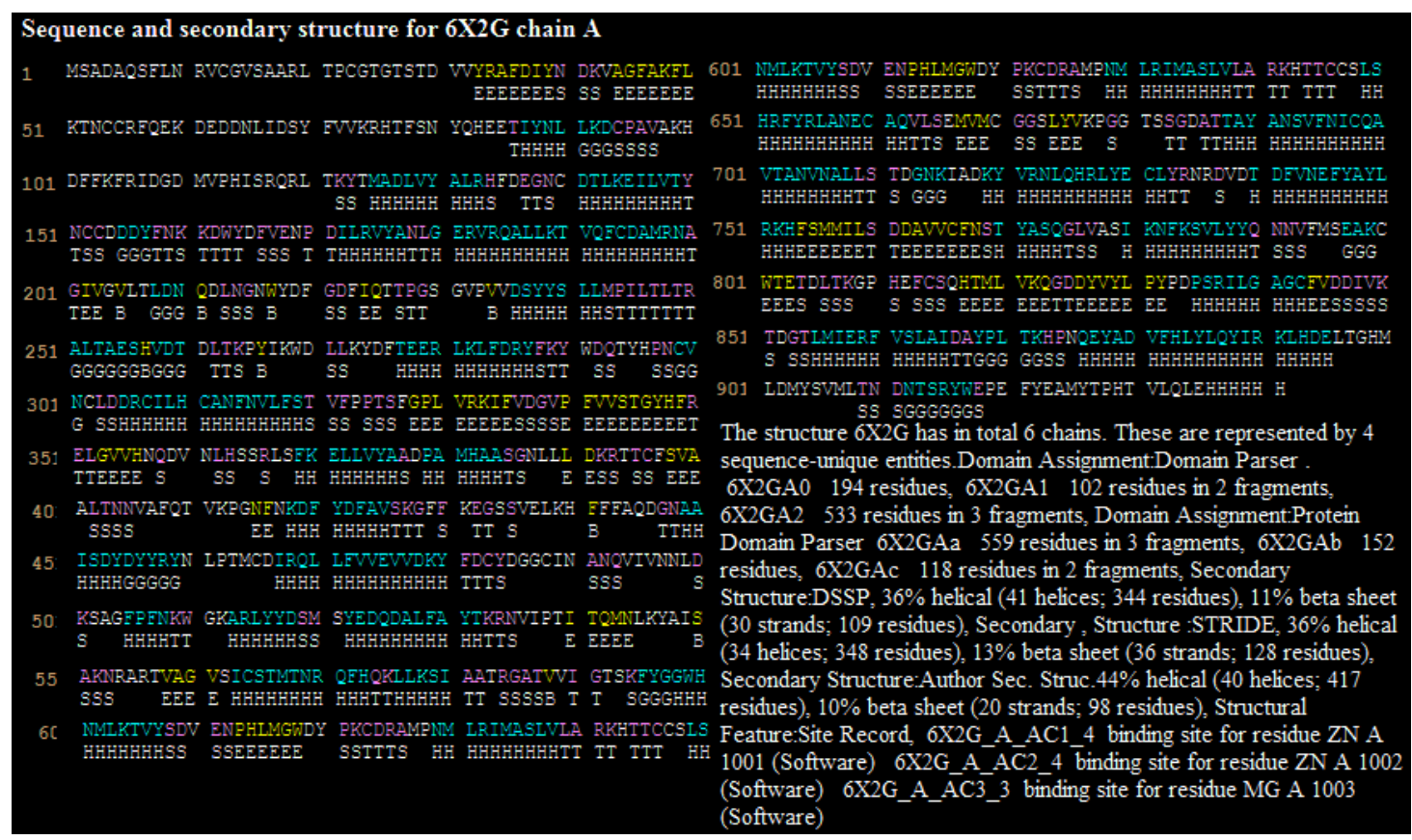

Figure 4. 6x2g-A binding site for residue MGA 1003 and the others. 


\section{Materials and Methods}

We calculated several genomes of COVID-19 data from GISAID, NCBI, and NMDC. Sequence alignment plus the strain Bat CoV RaTG13 used by MAFFT (https://mafft.cbrc.jp/alignment/software/). The protein sequences were obtained from NCBI web sites, and the proteins of COVID-19, such as protein sequences, were applied for analyzing the conserved domain. Some proteins were also applied for constructing 3-D structures via modeling and simulation. The PDB information was downloaded from the PDB database, and some COVID-19 proteins, such as 6x2g, are used for molecular docking (Fig.4).

By this study, a wide range of bioinformatics analyses were accomplished based on published biological protein sequences. Using molecular docking technology of DiscoveryStudio 201673, the receptor-ligand docking of viral proteins with human heme was simulated. Depending on the results of the bioinformatics analysis, the related molecular of the diseases was proposed.

\subsection{Simulations for interactions between the CoV2-RBD and the ACE2.}

It can be discussed about the charged residues for many of the components and binding interface of CoV2-RBD and the ACE2. Moreover, electrostatic interactions have critical points for the complex formation. Distances among the two mentioned proteins are key at the binding interfaces that are identified and summarized in Table 1 for the three representative models (Figure 5 \& Table 1).

The majority of those residues are preserved for models. The same simulations can be accomplished for the SARS-RBD/ACE2 complexes. Interestingly, the SARS-RBD counterpart in $\mathrm{CoV} 2-\mathrm{RBD}$ did not form near contacts with the $\mathrm{ACE}(2)$ in related simulations. The hydrogen bonds among the CoV2-RBD and ACE2 can be extracted using the VMD program. This work has been done based on our theoretical works [17-77]. Some extra program such as the noisy software (http://www.bioinf.uni-leipzig.de/Software/noisy/) has also been applied for this work [78-80].

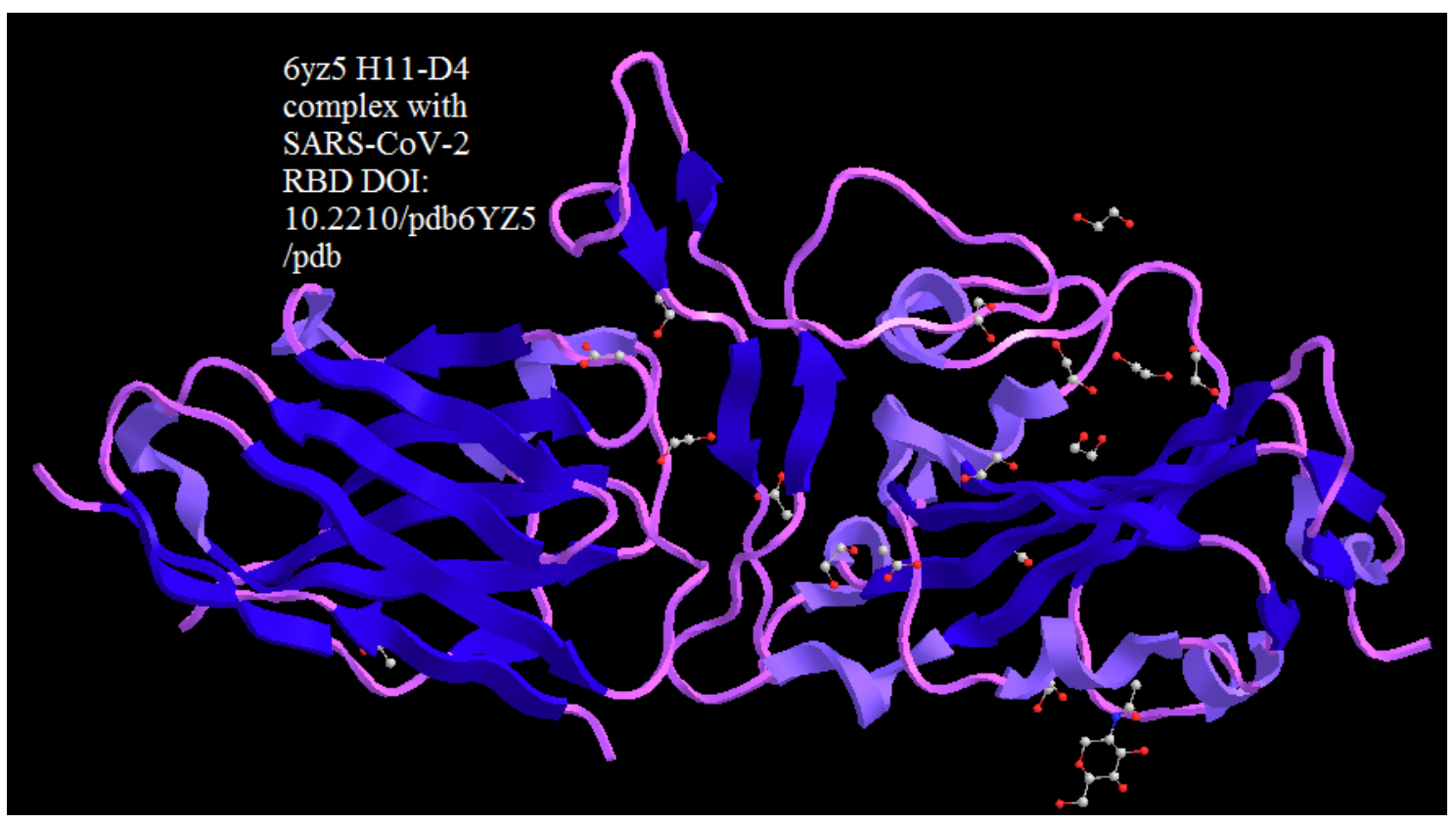

Figure 5. Severe acute respiratory syndrome, coronavirus 2, Lama glama. 
Table 1. Human-derived anti-SARS-CoV-2 S protein RBD neutralizing antibody and Nucleocapsid antibody (Contact residues); Host is HEK293 for all.

\begin{tabular}{|c|c|c|c|}
\hline Molecule & Cat. No. & Species & Product Description \\
\hline \multirow{8}{*}{ ACE2 } & AC2(H82E6) & Human & Biotinylated Human ACE2- ACEH Protein, His \\
\hline & $\mathrm{AC} 2(\mathrm{H} 82 \mathrm{~F} 9)$ & Human & Biotinylated Human ACE2- ACEH Protein, Fc \\
\hline & $\mathrm{AC} 2(\mathrm{H} 5257)$ & Human & Human ACE2-ACEH Protein, Fc Tag \\
\hline & $\mathrm{AC} 2(\mathrm{C} 52 \mathrm{H} 7)$ & Cynomolgus & Cynomolgus ACE2 / ACEH Protein, His \\
\hline & $\mathrm{AC} 2(\mathrm{H} 52 \mathrm{H} 8$ & Human & Human ACE2 / ACEH Protein, His Tag \\
\hline & $\mathrm{AC} 2(\mathrm{R} 5246)$ & Rat & Rat ACE2 / ACEH Protein, His Tag \\
\hline & AC2(M5248) & Mouse & Mouse ACE2 / ACEH Protein, His \\
\hline & $\mathrm{AC} 2(\mathrm{P} 5248)$ & Paguma larvata & Paguma larvata ACE2 / ACEH Protein, His \\
\hline \multirow{2}{*}{$\begin{array}{l}\text { Nucleocap } \\
\text { sid protein }\end{array}$} & NUN(V52H3 & HCoV-OC43 & HCoV-OC43 Nucleocapsid protein, His Tag \\
\hline & SPN(S52H5) & SARS & SARS S protein (R667A), His Tag \\
\hline \multirow{7}{*}{$\mathrm{S} 1$ protein } & $\mathrm{S} 1 \mathrm{~N}(\mathrm{C} 52 \mathrm{H} 3)$ & SARS-CoV-2 & SARS-CoV-2 (COVID-19) S1 protein, His Tag \\
\hline & S1N(C82E8) & SARS-CoV-2 & Biotinylated SARS-CoV-2 (COVID-19) S1 protein, \\
\hline & S1N(S52H5) & SARS & SARS S1 protein \\
\hline & $\mathrm{S} 1 \mathrm{~N}(\mathrm{C} 52 \mathrm{H} 4)$ & SARS-CoV-2 & SARS-CoV-2 (COVID-19) S1 protein, \\
\hline & S1N(C5255) & SARS-CoV-2 & SARS-CoV-2 (COVID-19) S1 protein \\
\hline & $\mathrm{S} 1 \mathrm{~N}(\mathrm{C} 5257)$ & SARS-CoV-2 & SARS-CoV-2 (COVID-19) S1 protein, Mouse IgG2a \\
\hline & $\mathrm{S} 1 \mathrm{~N}(\mathrm{C} 5256)$ & SARS-CoV-2 & SARS-CoV-2 (COVID-19) S1 protein (D614G), His Tag \\
\hline \multirow{13}{*}{$\begin{array}{l}\mathrm{S} 2 \text { protein } \\
\mathrm{S} \text { protein } \\
\mathrm{RBD}\end{array}$} & S2N(C52H5) & SARS-CoV-2 & SARS-CoV-2 (COVID-19) S2 protein, His Tag \\
\hline & SPD(C82E9) & SARS-CoV-2 & $\begin{array}{l}\text { Biotinylated SARS-CoV-2 (COVID-19) S protein RBD, } \\
\text { His,AvitagTM (MALS verified) }\end{array}$ \\
\hline & SPDC5255 & SARS-CoV-2 & $\begin{array}{l}\text { SARS-CoV-2 (COVID-19) S protein RBD, Fc Tag (MALS } \\
\text { verified) }\end{array}$ \\
\hline & SPDS52H6 & SARS & SARS S protein RBD, His Tag (MALS verified) \\
\hline & SPDC52H3 & SARS-CoV-2 & $\begin{array}{l}\text { SARS-CoV-2 (COVID-19) S protein RBD, His Tag (MALS } \\
\text { verified) }\end{array}$ \\
\hline & SPDC5259 & SARS-CoV-2 & $\begin{array}{l}\text { SARS-CoV-2 (COVID-19) S protein RBD, Mouse IgG2a Fc } \\
\text { Tag }\end{array}$ \\
\hline & SPDS52H4 & SARS-CoV-2 & SARS-CoV-2 (COVID-19) S protein RBD (V367F), His Tag \\
\hline & SPDS52H5 & SARS-CoV-2 & SARS-CoV-2 (COVID-19) S protein RBD (N354D), His Tag \\
\hline & SPD-S52H7 & SARS-CoV-2 & $\begin{array}{l}\text { SARS-CoV-2 (COVID-19) S protein RBD (W436R), His } \\
\text { Tag }\end{array}$ \\
\hline & SPD-S52H8 & SARS-CoV-2 & SARS-CoV-2 (COVID-19) S protein RBD (R408I), His Tag \\
\hline & SPD-S52H3 & SARS-CoV-2 & $\begin{array}{l}\text { SARS-CoV-2 (COVID-19) S protein } \\
\text { D364Y), His Tag }\end{array}$ \\
\hline & SPD-C52H4 & SARS-CoV-2 & SARS-CoV-2 (COVID-19) S protein RBD (G476S), His Tag \\
\hline & SPDC52H5 & SARS-CoV-2 & SARS-CoV-2 (COVID-19) S protein RBD (V483A), His Tag \\
\hline $\begin{array}{l}\text { S1 protein } \\
\text { CTD }\end{array}$ & S1DC52H3 & SARS-CoV-2 & SARS-CoV-2 (COVID-19) S1 protein CTD, His Tag \\
\hline \multirow{2}{*}{$\mathrm{S}$ protein } & SPNC52H4 & SARS-CoV-2 & $\begin{array}{l}\text { SARS-CoV-2 (COVID-19) S protein (R683A, R685A), His } \\
\text { Tag }\end{array}$ \\
\hline & SPNC52H8 & SARS-CoV-2 & SARS-CoV-2 (COVID-19) S protein (R683A, R685A), His \\
\hline $\begin{array}{l}\text { Envelope } \\
\text { protein }\end{array}$ & ENNC5128 & SARS-CoV-2 & SARS-CoV-2 (COVID-19) Envelope protein, His Tag \\
\hline $\begin{array}{l}\text { Papain } \\
\text { Protease }\end{array}$ & PAEC5148 & SARS-CoV-2 & SARS-CoV-2 (COVID-19) Papain-like Protease Protein, \\
\hline \multirow{3}{*}{$\begin{array}{l}\text { Nucleocap } \\
\text { sid protein }\end{array}$} & NUNC51H9 & SARS-CoV-2 & SARS-CoV-2 (COVID-19) Nucleocapsid protein, His Tag \\
\hline & NUNC5227 & SARS-CoV-2 & SARS-CoV-2 (COVID-19) Nucleocapsid protein, His Tag \\
\hline & NUNC81Q6 & SARS-CoV-2 & Biotinylated SARS-CoV-2 (COVID-19) Nucleocapsid \\
\hline $\begin{array}{l}\text { NSP7 } \\
\text { NSP8 }\end{array}$ & NS8C5125 & SARS-CoV-2 & SARS-CoV-2 (COVID-19) NSP7\&NSP8 Protein, His Tag \\
\hline $\begin{array}{l}\text { NSP16 } \\
\text { NSP10 }\end{array}$ & NS0C51W3 & SARS-CoV-2 & SARS-CoV-2 (COVID-19) NSP16\&NSP10 Heterodimer \\
\hline \multirow{4}{*}{$\mathrm{S} 1$ protein } & SINV52H3 & HCoV-NL63 & HCoV-NL63 S1 protein, His Tag \\
\hline & SINV52H4 & HCoV-229E & HCoV-229E S1 protein, His Tag \\
\hline & SINV52H5 & $\mathrm{HCoV}-\mathrm{OC} 43$ & HCoV-OC43 S1 protein, His Tag \\
\hline & SINV52H6 & HCoV-HKU1 & HCoV-HKU1(isolate N5) S1 protein, His Tag \\
\hline NSP1 & NS1C51H7 & SARS-CoV-2 & SARS-CoV-2 (COVID-19) NSP1 Protein, His Tag \\
\hline NSP7 & NS7C51H6 & SARS-CoV-2 & SARS-CoV-2 (COVID-19) NSP7 Protein, His Tag \\
\hline
\end{tabular}

\subsection{M.D. simulations.}

Molecular dynamics modeling for polypeptide-ligand complexes were accomplished using the Desmond software. The OPLS and charm force fields were applied for modeling the 
interactions of the protein-small molecules. Long-range electrostatic forces were estimated using the Particle-mesh Ewald (PME) software with a grid spacing of $0.75 \AA$ A. Nose-Hoover thermometry and Martyna-Tobias-Klein method were applied for maintaining the temperature and constant pressure, respectively. The formula of motion was considered using the multi-run RESPA by 3.0 fs time step for bonded and non-bonded interactions within a low cutoff. An outer time step of 5.0 fs was used for non-bonded forces beyond the cutoff.

\section{Results and Discussion}

The pdb format of crystal structures was first treated using the protein configuration by the Schrodinger software through docking grid generation. They are flexible docking, which is accomplished via default settings without the formation of intramolecular hydrogen bonds. The crystal ligands, N3, were covalently bonded to CYS amino acids. A new version of N3, N3' via breaking the covalent bond and filling in open valences, have been produced and then evaluated whether Glide flexible docking can rearrange the native binding poses. Moreover, the dataset of approved drugs was prepared using Drug-Bank, and a collection of PubChem structures that are similar to Lopinavir were made suitable docking screenings.

Lopinavir, a potent inhibitor of HIV-1 protease, was found effective in treating COVID19 patients. These kinds of strategies are thought to prepare highly detailed pictures of protein's interior dynamics. These small molecules tracking approaches were applied for determining the accessibilities of the active site in both SARS-CoV and COVID-19, and also, the local distribution approaches were applied for providing information about an overall distribution of related solvents in the protein interior. We also accomplished the time-window mode of the AQUA-DUCT (AQ) software for analyzing the water molecules via the cavities in a $15 \mathrm{~ns}$ time step (Fig.6).

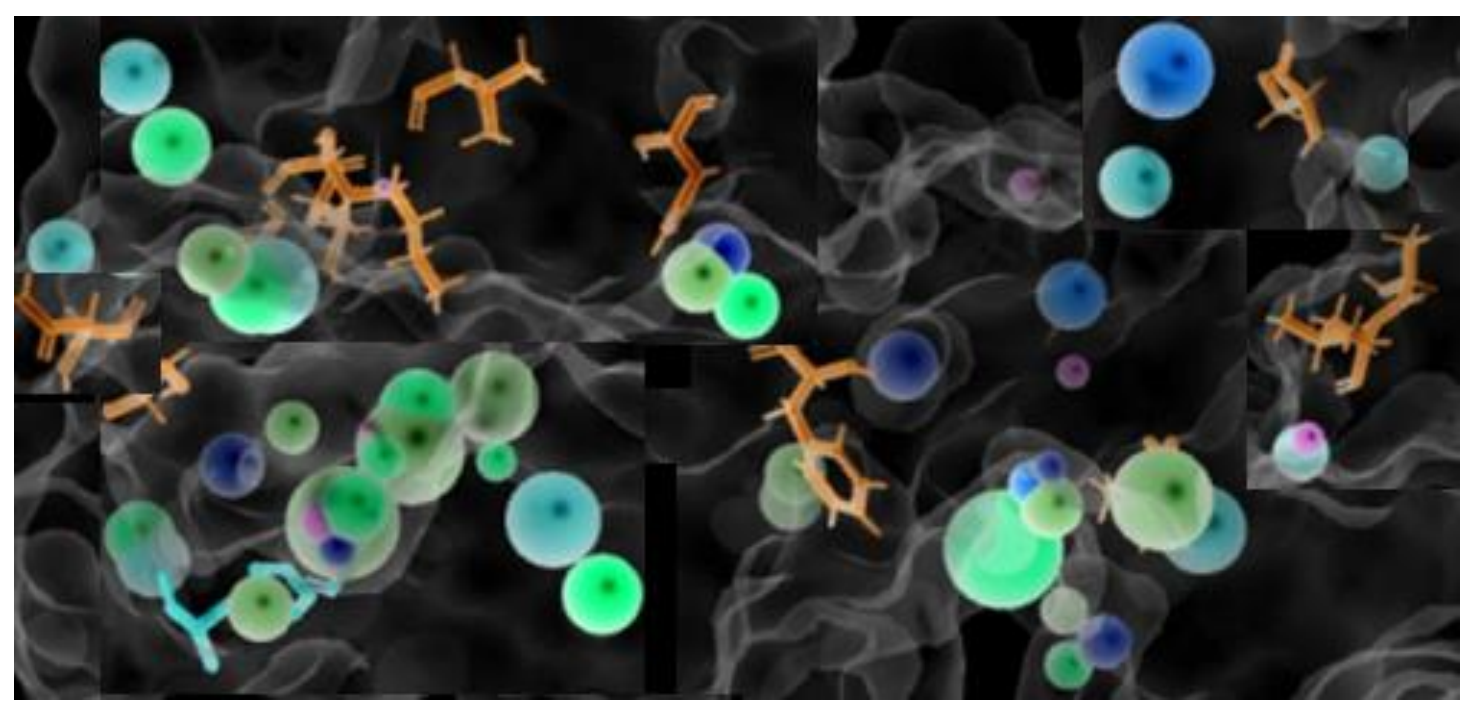

Figure 6. Important hot-spots localization of the COVID-19 in the hot-spots density.

Figure 6 presents the sizes and structures of the SARS main proteases. Since these molecules are completely similar, it might be expected that their binding pocket would also be very similar that explains there can be large differences among the accessibilities to the binding cavities and the structure of the cavities in response to a binding inhibitor. These results suggest that the SARS main proteases' binding cavities are highly flexible and change both in volume and structure significantly after ligand binding. Testing of Plasticity and flexibilities of the 
main proteases binding cavities are very important, especially focusing on the movements of loops surrounding their entrances and regulating the active sites' accessibility. The docking result exhibited one of the loops of the SARS-CoV is more flexible than the corresponding loops of two other structures. Such flexibilities could suggest that the presence of an inhibitor might stabilize the loops surrounding the active site. For preventing the diffusing virus, carrying and managing of patients are required, including early identification, rapid isolation, and timely establishment of infection prevention to control with mild disease. The global public health community should be considered the effects of mass gathering cancellations on the future well-being of communities via economic recession as well as through the spread of COVID-19.

\section{Conclusions}

This kind of information, which applied for anti-SARS-CoV-NSPs, can confirm our molecular simulation \& modeling. The grids between 15-20 $\AA$ were generated over the peptide-like inhibitors of all proteins and as well as for small-molecule inhibitors. As a result, the binding site for SARS-CoV-2 is restricted with hydrophilic residues with mines charged (ASP, Met, Gln, and GLU) and one also positively charged (Arg). Besides those residues, ASN-955 and VAL-951 residues also interact with the ligands. Therefore health-care workers must follow the guidelines and have not attempted to perform any virus isolation or characterization.

\section{Funding}

This research received no external funding.

\section{Acknowledgments}

Thanks to the Central Tehran Branch, Islamic Azad University for supporting computational software and all necessary equipment.

\section{Conflicts of Interest}

The authors declare no conflict of interest.

\section{References}

1. Lana, R.; Coellaho, F.C.; Gomes, M.F.; Cruz, O.G.; Bastos, L.S.; Villela, D.A.; et al.The novel coronavirus (SARS-CoV-2) emergency and the role of timely and effective national health surveillance. Rep Public Health 2020, 36, http://doi.org/10.1590/0102-311X00019620.

2. Baglivo, M.; Baronio, M.; Natalini, G.; Beccari, T.; Fuulcheri, P.C.; Petralia, P.; Michelini, S.; Fiorientini, G.; Miggiano, G.A.; Moressi, A.; Tonini, G.; Bertelli, M. Natural small molecules as inhibitors of coronavirus lipiddependent attachment to host cells a possible strategy for reducing SARS-COV-2 infectivity? Acta Biomed 2020, 91, 161-4, https://doi.org/10.23750/abm.v91i1.9402.

3. Thomso, G. COVID-19: social distancing, ACE 2 receptors, protease inhibitors and beyond? Int J Clin Prac 2020, https://doi.org/10.1111/ijcp.13503.

4. Lippi, G.; Plebani, M.; The critical role of laboratory medicine during coronavirus disease 2019, (COVID19) and other viral outbreaks. Clin Chem Lab Med 2020, https://doi.org/10.1515/cclm-2020-0240.

5. Karako, K.; Song, P.; Chen, Y.; Tang, W. Analysis of COVID-19 infection spread in Japan based on stochastic transition model. BioSci Tre 2020, 14, 134-138, https://doi.org/10.5582/bst.2020.01482.

6. Wu, A.; Peng, Y.; Huang, B.; Ding, X.; Wang, X.; Niu, P.; Meng, J.; Zhu, Z.; Zhang, Z.; Wang, J.; Sheng, J.; Quan, L.; Xia, Z.; Tan, W.; Cheng, G.; Jiang, T. Genome composition and divergence of the novel Coronavirus (2019-nCoV) originating in China. Cell Host Microbe 2020, 27, 325-328, https://doi.org/10.1016/j.chom.2020.02.001. 
7. Cheepsattayakorn, A.; Cheepsattayakorn, R. Proximal origin and phylogenetic analysis of COVID-19 (2019nCoV or SARS-CoV-2). EC Microbiol 2020.

8. Guo, Y.-R.; Cao, Q.-D.; Hong, Z.-S.; Tan, Y.-Y.; Chen, S.-D.; Jin, H.-J.; Tan, K.-S.; Wang, D.-Y.; Yan, Y. The origin, transmission and clinical therapies on coronavirus disease 2019 (COVID-19) outbreak-an update on the status. Milit Med Res 2020, 7, https://doi.org/10.1186/s40779-020-00240-0.

9. Rothan, H.A.; Byrareddy SN. The epidemiology and pathogenesis of coronavirus disease (COVID-19) outbreak. J Autoimm 2020, 109, https://doi.org/10.1016/j.jaut.2020.102433.

10. Koenig, K.L.; Beÿ, C.K.; McDonald, E.C. 2019-nCoV: the Identify-IsolateInform (3I) tool applied to a novel emerging Coronavirus. West J Emerg Med 2020, 21, 184-90, https://dx.doi.org/10.5811\%2Fwestjem.2020.1.46760.

11. Dany, L. COVID-19: protecting health-care workers. Lancet 2020, 395, https://doi.org/10.1016/S01406736(20)30627-9.

12. McCloskey, B.; Zumla, A.; Ippolito, G.; Blumberg, L.; Arbon, P.; Cicero, A.; Endericks, T.; Lim, P.L.; Borodina, M. Mass gathering events and reducing further global spread of COVID-19: a political and public health dilemma. The Lancet 2020, 395, 1096-1099, https://doi.org/10.1016/S0140-6736(20)30681-4.

13. Jin, Z.; Du, X.; Xu, Y.; Deng, Y.; Liu, M.; Zhao, Y.; Zhang, B.; Li, X.; Zhang, L.; Peng, C.; Duan, Y.; Yu, J.; Wang, L.; Yang, K.; Liu, F.; Jiang, R.; Yang, X.; You, T.; Liu, X.; Yang, X.; Bai, F.; Liu, H.; Liu, X.; Guddat, L.W.; Xu, W.; Xiao, G.; Qin, C.; Shi, Z.; Jiang, H.; Rao, Z.; Yang, H. Structure of M\&lt;sup\&gt;pro\&lt;/sup\&gt; from COVID-19 virus and discovery of its inhibitors. bioRxiv 2020, https://doi.org/10.1101/2020.02.26.964882.

14. Wu, Y.; Guo, C.; Tang, L.; Hong, Z.; Zhou, J.; Dong, X.; Yin, H.; Xiao, Q.; Tang, Y.; Qu, X.; Kuang, L.; Fang, X.; Mishra, N.; Lu, J.; Shan, H.; Jiang, G.; Huang, X. Prolonged presence of SARS-CoV-2 viral RNA in faecal samples. The Lancet Gastroenterology \& Hepatology 2020, 5, 434-435, https://doi.org/10.1016/S2468-1253(20)30083-2.

15. Mitjà, O.; Clotet, B. Use of antiviral drugs to reduce COVID-19 transmission. The Lancet Global Health 2020, 8, e639-e640, https://doi.org/10.1016/S2214-109X(20)30114-5.

16. Bashyam, A.M.; Feldman, S.R. Should patients stop their biologic treatment during the COVID-19 pandemic. Journal of Dermatological Treatment 2020, 31, 317-318, https://doi.org/10.1080/09546634.2020.1742438.

17. Mollaamin, F.; Monajjemi, M. DFT outlook of solvent effect on function of nano bioorganic drugs. Physics and Chemistry of Liquids 2012, 50, 596-604, https://doi.org/10.1080/00319104.2011.646444.

18. Mollaamin, F.; Gharibe, S.; Monajjemi, M. Synthesis of various nano and micro ZnSe morphologies by using hydrothermal method. International Journal of Physical Sciences 2011, 6, 1496-1500.

19. Monajjemi, M. Graphene/(h-BN)n/X-doped raphene as anode material in lithium ion batteries $(\mathrm{X}=\mathrm{Li}, \mathrm{Be}$, B AND N,). Macedonian Journal of Chemistry and Chemical Engineering 2017, 36, 101-118, http://dx.doi.org/10.20450/mjcce.2017.1134.

20. Monajjemi, M. Cell membrane causes the lipid bilayers to behave as variable capacitors: A resonance with self-induction of helical proteins. Biophysical Chemistry 2015, 207, 114-127, https://doi.org/10.1016/j.bpc.2015.10.003.

21. Monajjemi, M. Study of CD5+ Ions and Deuterated Variants $(\mathrm{CHxD}(5-\mathrm{x})+)$ : An Artefactual Rotation. Russian Journal of Physical Chemistry A 2018, 92, 2215-2226.

22. Monajjemi, M. Liquid-phase exfoliation (LPE) of graphite towards graphene: An ab initio study. Journal of Molecular Liquids, 2017, 230, 461-472, https://doi.org/10.1016/j.molliq.2017.01.044.

23. Jalilian, H.; Monajjemi, M. Capacitor simulation including of X-doped graphene (X $=\mathrm{Li}, \mathrm{Be}, \mathrm{B})$ as two electrodes and $(\mathrm{h}-\mathrm{BN}) \mathrm{m}(\mathrm{m}=1-4)$ as the insulator. Japanese Journal of Applied Physics 2015, 54, 0851017, https://doi.org/10.33263/BRIAC106.66956705

24. Ardalan, T.; Ardalan, P.; Monajjemi, M. Nano theoretical study of a C 16 cluster as a novel material for vitamin C carrier. Fullerenes Nanotubes and Carbon Nanostructures 2014, 22, 687-708, https://doi.org/10.1080/1536383X.2012.717561.

25. Mahdavian, L.; Monajjemi, M.; Mangkorntong, N. Sensor response to alcohol and chemical mechanism of carbon nanotube gas sensors Fullerenes Nanotubes and Carbon Nanostructures 2009, 17, 484-495, https://doi.org/10.1080/15363830903130044.

26. Monajjemi, M.; Najafpour, J. Charge density discrepancy between NBO and QTAIM in single-wall armchair carbon nanotubes. Fullerenes Nanotubes and Carbon Nano structures 2014, 22, 575-594, https://doi.org/10.1080/1536383X.2012.702161.

27. Monajjemi, M.; Hosseini, M.S. Non bonded interaction of B16 N16 nano ring with copper cations in point of crystal fields. Journal of Computational and Theoretical Nanoscience 2013, 10, 2473-2477.

28. Monajjemi, M.; Mahdavian, L.; Mollaamin, F. Characterization of nanocrystalline silicon germanium film and nanotube in adsorption gas by Monte Carlo and Langevin dynamic simulation. Bulletin of the Chemical Society of Ethiopia 2008, 22, 277-286, https://doi.org/10.4314/bcse.v22i2.61299.

29. Lee, V.S.; Nimmanpipug, P.; Mollaamin, F.; Thanasanvorakun, S.; Monajjemi, M. Investigation of single wall carbon nanotubes electrical properties and normal mode analysis: Dielectric effects. Russian Journal of Physical Chemistry A 2009, 83, 2288-2296, https://doi.org/10.1134/S0036024409130184. 
30. Mollaamin, F.; Najafpour, J.; Ghadami, S.; Akrami, M.S.; Monajjemi, M. The electromagnetic feature of B $\mathrm{N} \mathrm{H}(\mathrm{x}=0,4,8,12,16$, and 20) nano rings:Quantum theory of atoms in molecules/NMR approach. Journal of Computational and Theoretical Nanoscience 2014, 11, 1290-1298.

31. Monajjemi, M.; Mahdavian, L.; Mollaamin, F.; Honarparvar, B. Thermodynamic investigation of enolketo tautomerism for alcohol sensors based on carbon nanotubes as chemical sensors. Fullerenes Nanotubes and Carbon Nanostructures 2010, 18, 45-55, https://doi.org/10.1080/15363830903291564.

32. Monajjemi, M.; Ghiasi, R.; Seyed, S.M.A. Metal-stabilized rare tautomers: N4 metalated cytosine ( $\mathrm{M}=\mathrm{Li}$, $\mathrm{Na}, \mathrm{K}, \mathrm{Rb}$ and $\mathrm{Cs}$ ), theoretical views. Applied Organometallic Chemistry 2003, 17, 635-640, https://doi.org/10.1002/aoc.469.

33. Ilkhani, A.R.; Monajjemi, M. The pseudo Jahn-Teller effect of puckering in pentatomic unsaturated rings $\mathrm{C}$ $\mathrm{AE}, \mathrm{A}=\mathrm{N}, \mathrm{P}, \mathrm{As}, \mathrm{E}=\mathrm{H}, \mathrm{F}, \mathrm{Cl}$.Computational and Theoretical Chemistry 2015, 1074, 19-25, http://dx.doi.org/10.1016\%2Fj.comptc.2015.10.006.

34. Monajjemi, $\mathrm{M}$. Non-covalent attraction of $\mathrm{B} \mathrm{N}$ and repulsion of $\mathrm{B} \mathrm{N}$ in the $\mathrm{B} \mathrm{N}$ ring: a quantum rotatory due to an external field. Theoretical Chemistry Accounts 2015, 134, 1-22, https://doi.org/10.1007/s00214-0151668-9.

35. Monajjemi, M.; Naderi, F.; Mollaamin, F.; Khaleghian, M. Drug design outlook by calculation of second virial coefficient as a nano study. Journal of the Mexican Chemical Society 2012, 56, 207-211, https://doi.org/10.29356/jmcs.v56i2.323.

36. Monajjemi, M.; Bagheri, S.; Moosavi, M.S. Symmetry breaking of B2N(-,0,+): An aspect of the electric potential and atomic charges. Molecules 2015, 20, 21636-21657, https://doi.org/10.3390/molecules201219769.

37. Monajjemi, M.; Mohammadian, N.T. S-NICS: An aromaticity criterion for nano molecules. Journal of Computational and Theoretical Nanoscience 2015, 12, 4895-4914, https://doi.org/10.1166/jctn.2015.4458.

38. Monajjemi, M.; Ketabi, S.; Hashemian, Z.M.; Amiri, A. Simulation of DNA bases in water: Comparison of the Monte Carlo algorithm with molecular mechanics force fields. Biochemistry (Moscow) 2006, 71, 1-8, https://doi.org/10.1134/s0006297906130013.

39. Monajjemi, M.; Lee, V.S.; Khaleghian, M.; Honarparvar, B.; Mollaamin, F. Theoretical Description of Electromagnetic Nonbonded Interactions of Radical, Cationic, and Anionic NH2BHNBHNH2 Inside of the B18N18 Nanoring. J. Phys. Chem C 2010, 114, 15315-15330, https://doi.org/10.1021/jp104274z.

40. Monajjemi, M.; Boggs, J.E. A New Generation of BnNn Rings as a Supplement to Boron Nitride Tubes and Cages. J. Phys. Chem. A 2013, 117, 1670-1684, http://dx.doi.org/10.1021/jp312073q.

41. Monajjemi, M. Non bonded interaction between BnNn (stator) and BN B (rotor) systems: A quantum rotation in IR region. Chemical Physics 2013, 425, 29-45, https://doi.org/10.1016/j.chemphys.2013.07.014.

42. Monajjemi, M.; Robert, W.J.; Boggs, J.E. NMR contour maps as a new parameter of carboxyl's OH groups in amino acids recognition: A reason of tRNA-amino acid conjugation. Chemical Physics 2014, 433, 1-11, https://doi.org/10.1016/j.chemphys.2014.01.017.

43. Monajjemi, M. Quantum investigation of non-bonded interaction between the B15N15 ring and BH2NBH2 (radical, cation, and anion) systems: a nano molecularmotor. Struct Chem 2012, 23, 551-580, http://dx.doi.org/10.1007/s11224-011-9895-8.

44. Monajjemi, M. Metal-doped graphene layers composed with boron nitride-graphene as an insulator: a nanocapacitor. Journal of Molecular Modeling 2014, 20, https://doi.org/10.1007/s00894-014-2507-y.

45. Mollaamin, F.; Monajjemi, M.; Mehrzad, J. Molecular Modeling Investigation of an Anti-cancer Agent Joint to SWCNT Using Theoretical Methods. Fullerenes, Nanotubes and Carbon Nanostructures 2014, 22, 738751, https://doi.org/10.1080/1536383X.2012.731582.

46. Monajjemi, M.; Ketabi, S.; Amiri, A. Monte Carlo simulation study of melittin: protein folding and temperature ependence. Russian journal of physical chemistry 2006, 80, S55-S62, https://doi.org/10.1134/S0036024406130103.

47. Monajjemi, M.; Heshmata, M.; Haeria, H.H. QM/MM model study on properties and structure of some antibiotics in gas phase: Comparison of energy and NMR chemical shift. Biochemistry (Moscow) 2006, 71, S113-S122, https://doi.org/10.1134/S0006297906130190.

48. Monajjemi, M.; Afsharnezhad, S.; Jaafari, M.R.; Abdolahi, T.; Nikosade, A.; Monajemi, H. NMR shielding and a thermodynamic study of the effect of environmental exposure to petrochemical solvent on DPPC, an important component of lung surfactant. Russian Journal of Physical Chemistry A 2007, 81, 1956-1963, https://doi.org/10.1134/S0036024407120096.

49. Mollaamin, F.; Noei, M.; Monajjemi, M.; Rasoolzadeh, R. Nano theoretical studies of fMET-tRNA structuren in protein synthesis of prokaryotes and its comparison with the structure of fALA-tRNA. African journal of microbiology research 2011, 5, 2667-2674, https://doi.org/10.5897/AJMR11.310.

50. Monajjemi, M.; Heshmat, M.; Haeri, H.H.; Kaveh, F. Theoretical study of vitamin properties from combined QM-MM methods: Comparison of chemical shifts and energy. Russian Journal of Physical Chemistry 2006, 80, 1061-1068, https://doi.org/10.1134/S0036024406070119.

51. Monajjemi, M.; Chahkandi, B. Theoretical investigation of hydrogen bonding in Watson-Crick, Hoogestein and their reversed and other models: comparison and analysis for configurations of adenine-thymine base 
pairs in 9 models. Journal of Molecular Structure: THEOCHEM 2005, 714, 43-60, https://doi.org/10.1016/j.theochem.2004.09.048.

52. Monajjemi, M.; Honarparvar, B.; Haeri, H.H.; Heshmat, M. An ab initio quantum chemical investigation of solvent-induced effect on 14N-NQR parameters of alanine, glycine, valine, and serine using a polarizable continuum model. Russian Journal of Physical Chemistry 2006, 80, S40-S44, https://doi.org/10.1134/S0036024406130073.

53. Monajjemi, M.; Seyed Hosseini, M. Non Bonded Interaction of B16N16 Nano Ring with Copper Cations in Point of Crystal Fields. Journal of Computational and Theoretical Nanoscience 2013, 10, 2473-2477, https://doi.org/10.1166/jctn.2013.3233.

54. Monajjemi, M.; Farahani, N.; Mollaamin, F. Thermodynamic study of solvent effects on nanostructures: phosphatidylserine and phosphatidylinositol membranes. Physics and Chemistry of Liquids 2012, 50, 161172, https://doi.org/10.1080/00319104.2010.527842.

55. Monajjemi, M.; Ahmadianarog, M. Carbon Nanotube as a Deliver for Sulforaphane in Broccoli Vegetable in Point of Nuclear Magnetic Resonance and Natural Bond Orbital Specifications. Journal of Computational and Theoretical Nanoscience 2014, 11, 1465-1471, https://doi.org/10.1166/jctn.2014.3519.

56. Monajjemi, M.; Ghiasi, R.; Ketabi, S.; Passdar, H.; Mollaamin, F. A Theoretical Study of Metal-Stabilised Rare Tautomers Stability: N4 Metalated Cytosine (M=Be2+, Mg2+, Ca2+, Sr2+ and $\mathrm{Ba} 2+)$ in Gas Phase and Different. Journal of Chemical Research 2004, 1, 11-18, https://doi.org/10.3184/030823404323000648.

57. Monajjemi, M.; Baei, M.T.; Mollaamin, F. Quantum mechanic study of hydrogen chemisorptions on nanocluster vanadium surface. Russian Journal of Inorganic Chemistry 2008, 53, 1430-1437, https://doi.org/10.1134/S0036023608090143.

58. Mollaamin, F.; Baei, M.T.; Monajjemi, M.; Zhiani, R.; Honarparvar, B. A DFT study of hydrogen chemisorption on V (100) surfaces. Russian Journal of Physical Chemistry A, Focus on Chemistry 2008, 82, 2354-2361, https://doi.org/10.1134/S0036024408130323.

59. Monajjemi, M.; Honarparvar, B.; Nasseri, S.M.; Khaleghian, M. NQR and NMR study of hydrogen bonding interactions in anhydrous and monohydrated guanine cluster model: A computational study. Journal of Structural Chemistry 2009, 50, 67-77, https://doi.org/10.1007/s10947-009-0009-z.

60. Monajjemi, M.; Aghaie, H.; Naderi, F. Thermodynamic study of interaction of TSPP, CoTsPc, and FeTsPc with calf thymus DNA. Biochemistry (Moscow) 2007, 72, 652-657, https://doi.org/10.1134/S0006297907060089.

61. Monajjemi, M.; Heshmat, M.; Aghaei, H.; Ahmadi, R.; Zare, K. Solvent effect on 14N NMR shielding of glycine, serine, leucine, and threonine: Comparison between chemical shifts and energy versus dielectric constant. Bulletin of the Chemical Society of Ethiopia 2007, 21, 111-116, https://doi.org/10.4314/bcse.v21i1.61387.

62. Monajjemi, M.; Rajaeian, E.; Mollaamin, F.; Naderi, F.; Saki, S. Investigation of NMR shielding tensors in 1,3 dipolar cycloadditions: solvents dielectric effect. Physics and Chemistry of Liquids 2008, 46, 299-306, https://doi.org/10.1080/00319100601124369.

63. Mollaamin, F.; Varmaghani, Z.; Monajjemi, M. Dielectric effect on thermodynamic properties in vinblastine by DFT/Onsager modelling. Physics and Chemistry of Liquids 2011, 49, 318-336, https://doi.org/10.1080/00319100903456121.

64. Monajjemi, M.; Honaparvar, B.; Khalili Hadad, B.; Ilkhani, A.; Mollaamin, F. Thermo-Chemical Investigation and NBO Analysis of Some anxileotic as Nano- Drugs. African journal of pharmacy and pharmacology 2010, 4, 521-529, https://doi.org/10.33263/BRIAC106.66956705

65. Monajjemi, M.; Khaleghian, M.; Mollaamin, F. Theoretical study of the intermolecular potential energy and second virial coefficient in the mixtures of $\mathrm{CH} 4$ and $\mathrm{Kr}$ gases: a comparison with experimental data. Molecular Simulation 2010, 36, 865-870, https://doi.org/10.1080/08927022.2010.489557.

66. Monajjemi, M.; Khosravi, M.; Honarparvar, B.; Mollaamin, F. Substituent and solvent effects on the structural bioactivity and anticancer characteristic of catechin as a bioactive constituent of green tea. International Journal of Quantum Chemistry 2011, 111, 2771-2777, https://doi.org/10.1002/qua.22612.

67. Tahan, A.; Monajjemi, M. Solvent dielectric effect and side chain mutation on the structural stability of Burkholderia cepacia lipase active site: a quantum mechanical/molecular mechanics study. Acta Biotheor 2011, 59, 291-312, https://doi.org/10.1007/s10441-011-9137-x.

68. Monajjemi, M.; Khaleghian, M. EPR Study of Electronic Structure of [CoF6]3-and B18N18 Nano Ring Field Effects on Octahedral Complex. Journal of Cluster Science 2011, 22, 673-692, https://doi.org/10.1007/s10876-011-0414-2.

69. Monajjemi, M.; Mollaamin, F. Molecular Modeling Study of Drug-DNA Combined to Single Walled Carbon Nanotube. Journal of Cluster Science 2012, 23, 259-272, https://doi.org/10.1007/s10876-011-0426-y.

70. Mollaamin, F.; Monajjemi, M. Fractal Dimension on Carbon Nanotube-Polymer Composite Materials Using Percolation Theory. Journal of Computational and Theoretical Nanoscience 2012, 9, 597-601, https://doi.org/10.1166/jctn.2012.2067.

71. Mahdavian, L.; Monajjemi, M. Alcohol sensors based on SWNT as chemical sensors: Monte Carlo and Langevin dynamics simulation. Microelectronics Journal 2010, 41, 142-149, https://doi.org/10.1016/j.mejo.2010.01.011. 
72. Monajjemi, M.; Falahati, M.; Mollaamin, F. Computational investigation on alcohol nanosensors in combination with carbon nanotube: a Monte Carlo and ab initio simulation. Ionics 2013, 19, 155-164, https://doi.org/10.1007/s11581-012-0708-X.

73. Monajjemi, M. Molecular vibration of dopamine neurotransmitter: a relation between its normal modes and harmonic notes. Biointerface Research in Applied Chemistry 2019, 9, 3956-3962, https://doi.org/10.33263/BRIAC93.956962.

74. Mollaamin, F.; Naiemi, M.; Monajjemi, M. Vinblastine and vincristine as anticancer molecules stopping the tubulin dimers, Letters in applied nano bio sciences 2019, 9, 870-874, https://doi.org/10.33263/LIANBS91.870874.

75. Mollaamin, F.; Monajjemi, M, Harmonic Linear Combination and Normal Mode Analysis of Semiconductor Nanotubes Vibrations., Journal of Computational and Theoretical Nanoscience, 2015, 12 (6), 1030-1039.

76. Ghalandari, B.; Monajjemi, M.; Mollaamin, F.; Theoretical investigation of carbon nanotube Binding to DNA in View of Drug Delivery. Journal of Computational and Theoretical Nanoscience , 2011, 8 (7), 12121219.

77. Monajjemi, M., Mahdavian, L.; Mollaamin, F.; Khaleghian, M.; Interaction of Na, Mg, Al, Si with carbon nanotube (CNT): NMR and IR study.,Russian Journal of Inorganic Chemistry 54 (9),1465 1473.

78. Andreas W. M.Dress.; Christoph Flamm.; Guido Fritzsch .; Stefan Grünewald.; Matthias Kruspe.; Sonja J. Prohaska.; Peter F. Stadler Noisy: identification of problematic columns in multiple sequence alignments. Algorithms Mol Biol 2008, 3, 7, https://doi.org/10.1186/1748-7188-3-7.

79. Stefan, Grünewald.; Kristoffer, Forslund.; Andreas, W.; M. Dress.; Vincent Moulton QNet: An Agglomerative Method for the Construction of Phylogenetic Networks from Weighted Quartets. Mol Biol Evol 2007, 24, 532-538, https://doi.org/10.1093/molbev/msl180.

80. David Bryant, Vincent Moulton Neighbor-Net: An Agglomerative Method for the Construction of Phylogenetic Networks. Mol Biol Evol 2004, 21, 255-265, https://doi.org/10.1093/molbev/msh018s. 